\title{
Disease Course of Lower Respiratory Tract Infection With a Bacterial Cause
}

\author{
Jolien Teepe, $M D, M S c^{1}$ \\ Berna D. L. Broekbuizen, MD, $P b D^{1}$ \\ Katherine Loens, $\mathrm{PbD}^{2}$ \\ Christine Lammens, MSc ${ }^{2}$ \\ Margareta Ieven, $\mathrm{PbD}^{2}$ \\ Herman Goossens, $M D, P_{b D^{2}}$ \\ Paul Little, MD, $P b D^{3}$ \\ Christopher C. Butler, $M D, P b D^{4,5}$ \\ Samuel Coenen, $M D, P b D^{2,6}$ \\ Maciek Godycki-Cwirko, $M D, P b D^{7}$ \\ Theo Verbeij, $M D, P b D^{1}$ \\ on behalf of the GRACE Consortium \\ Julius Center for Health Sciences and \\ Primary Care, University Medical Center \\ Utrecht, Utrecht, the Netherlands \\ ${ }^{2}$ University of Antwerp, Laboratory of \\ Medical Microbiology, Vaccine \& Infectious \\ Diseases Institute (VAXINFECTIO), Ant- \\ werp, Belgium \\ ${ }^{3}$ University of Southampton Medical \\ School, Primary Care Medical Group, \\ Southampton, United Kingdom \\ ${ }^{4}$ Nuffield Department of Primary Care \\ Health Sciences, Oxford University, \\ Oxford, United Kingdom \\ ${ }^{5}$ Cwm Taf University Health Board, Aber- \\ cynon, United Kingdom \\ ${ }^{6}$ University of Antwerp, Centre for Gen- \\ eral Practice, Department of Primary and \\ Interdisciplinary Care (ELIZA), Antwerp, \\ Belgium \\ ${ }^{7}$ Faculty of Health Sciences, Medical Uni- \\ versity of Lodz, Lodz, Poland

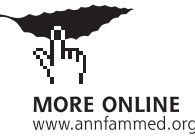 \\ Conflicts of interest: authors report none.
}

\section{CORRESPONDING AUTHOR}

Jolien Teepe, MD, MSc

Julius Center for Health Sciences and Primary Care

University Medical Center Utrecht

Stratenum 6.131, PO Box 85500

3508 GA Utrecht

The Netherlands

j.teepe-2@umcutrecht.nl

\begin{abstract}
PURPOSE Bacterial pathogens are assumed to cause an illness course different from that of nonbacterial causes of acute cough, but evidence is lacking. We evaluated the disease course of lower respiratory tract infection (LRTI) with a bacterial cause in adults with acute cough.
\end{abstract}

METHODS We conducted a secondary analysis of a multicenter European trial in which 2,061 adults with acute cough (28 days' duration or less) were recruited from primary care and randomized to amoxicillin or placebo. For this analysis only patients in the placebo group $(n=1,021)$ were included, reflecting the natural course of disease. Standardized microbiological and serological analyses were performed at baseline to define a bacterial cause. All patients recorded symptoms in a diary for 4 weeks. The disease course between those with and without a bacterial cause was compared by symptom severity in days 2 to 4 , duration of symptoms rated moderately bad or worse, and a return consultation.

RESULTS Of 1,021 eligible patients, 187 were excluded for missing diary records, leaving 834 patients, of whom 162 had bacterial LRTI. Patients with bacterial LRTI had worse symptoms at day 2 to 4 after the first office visit $(P=.014)$ and returned more often for a second consultation, $27 \%$ vs $17 \%$, than those without bacterial LRTI $(P=.004)$. Resolution of symptoms rated moderately bad or worse did not differ $(P=.375)$.

CONCLUSIONS Patients with acute bacterial LRTI have a slightly worse course of disease when compared with those without an identified bacterial cause, but the relevance of this difference is not meaningful.

Ann Fam Med 2016;14:534-539. doi: 10.1370/afm.1974.

\section{INTRODUCTION}

L ower respiratory tract infections (LRTIs) are among the most common reasons for consulting in primary care ${ }^{1}$ and physicians usually treat LRTI empirically based on clinical assessment without microbiological testing for the causal pathogen. Bacterial pathogens are often assumed to result in a different illness course than nonbacterial causes of acute cough, but knowledge of actual difference is lacking. In the few studies where potential pathogens have been systematically isolated from primary care patients with LRTI, a bacterial pathogen was identified in $19 \%$ to $43 \%$ of patients. ${ }^{1-4}$ Difference in illness course, however, was not evaluated in these studies. Knowledge of actual illness course of bacterial LRTI compared with other LRTIs may be helpful in several ways. Physicians fear missing bacterial LRTI because they generally assume that disease course is more severe and prolonged in these patients and prescribe antibiotics as a defensive strategy. ${ }^{5}$ As many of these antibiotics may not benefit patients, cause unwanted effects, and drive antimicrobial resistance, ${ }^{6-9}$ insight into the illness course of bacterial LRTI untreated with antibiotics could help guide empirical antibiotic prescribing, support a strategy of initial observation (watchful waiting), and help set evidencebased expectations about the disease course for patients. 
The aim of the present study was to describe the illness course of patients consulting in primary care with LRTI in whom a bacterial pathogen was isolated, and to compare their illness course with that of LRTI patients with no bacterial pathogen.

\section{METHODS}

\section{Design and Study Population}

This study was based on a secondary analysis of a randomized, placebo-controlled trial of amoxicillin for LRTI in 16 primary care networks in 12 European countries from October 2007 until April 2010. More details on this GRACE-10 study (Genomics to combat Resistance against Antibiotics in Community-acquired LRTI in Europe) have been reported elsewhere. ${ }^{10}$ Recruited networks had access to a minimum of 20,000 patients. Because LRTIs are common, many more eligible patients consulted their clinicians during the recruitment period than were invited to participate in this study. As a result, we did not achieve the goal of recruiting all consecutive, eligible patients. Nevertheless, we assume that this study sample resulted in limited selection bias, because participating clinicians reported that the main reason not to include all eligible patients was time constraint. ${ }^{11}$ Moreover, we found no relevant differences in patient characteristics compared with the observational study of Butler et $\mathrm{al}_{1}{ }^{6}$ done earlier in the same recruiting network.

Eligible patients were aged 18 years and older who consulted their physician for the first time with an acute cough (duration of 28 days or less) as the main symptom or where cough was not the most prominent symptom, but the physician considered an acute LRTI as the main diagnosis. Exclusion criteria were clinically suspected pneumonia ${ }^{12}$ based on focal chest signs (focal crepitation and bronchial breathing) and systemic features (high fever, vomiting, severe diarrhea), pregnancy, allergy to penicillin, treatment with antibiotics in the previous month, and immunodeficiency disorder. Additionally, patients allocated to amoxicillin or patients who did not return their follow-up diary were excluded. The study was approved by ethics committees in all participating countries, and all participants provided written informed consent.

\section{Measurements}

\section{Symptoms}

Physicians recorded patients' clinical signs and comorbidities on a case report form. They also recorded 14 baseline symptoms (cough, phlegm, shortness of breath, wheeze, runny nose, fever, chest pain, muscle aching, headache, disturbed sleep, feeling generally unwell, interference with normal activities/work, confusion/ disorientation, and diarrhea) on a 4-point Likert scale that ranged from no problem to severe problem. Baseline symptom severity was calculated by summing the scores of the symptoms and rescaling the scores to make them range between 0 and 100. Patients filled in a daily symptom diary during their illness for up to 28 days for the same symptoms on a 7-point Likert scale that ranged from no problem to severe problem. This diary was previously validated and shown to be sensitive to change. ${ }^{13}$

\section{Respiratory Sample}

A sputum sample from a productive cough (not available for all) and a nasopharyngeal swab were collected from each patient at day 1, before any antibiotic therapy was started. Sputa were sent to the local laboratory and processed immediately. Direct microscopy, Gram stain, and culture were performed according to a standardized protocol (Supplemental Appendix 1, http://www.annfammed.org/content/14/6/534/suppl/DC1). Nasopharyngeal swabs, put in Universal Transport Medium (Copan Diagnostics) and in skimmed milk medium, were sent to the laboratory of the University of Antwerp for bacterial and viral polymerase chain reaction (PCR) analysis.

\section{Chest Radiograph}

All patients underwent chest radiography within 7 days of first visit, preferably within 3 days. Pneumonia was determined by radiologists, blinded to all other information, who judged chest radiographs using a standard operating procedure (Supplemental Appendix 2, http:// www.annfammed.org/content/14/6/534/suppl/DC1). ${ }^{11}$

\section{Definition of Bacterial Infection}

Bacterial infection was defined as Streptococcus pneumoniae, Haemopbilus influenzae, Mycoplasma pneumoniae, Bordetella pertussis, Legionella pneumopbila in respiratory samples or serological evidence for $M$ pneumoniae infection. Chlamydia pneumoniae was not included because its clinical relevance is unclear. ${ }^{1,14} S$ pneumoniae and $H$ influenzae infections were considered present when a microorganism was isolated from sputum (ratio of 1 or more white blood cells to epithelial cells as a criterion for good quality) or a nasopharyngeal swab. B pertussis infection was determined by PCR (from nasopharyngeal swabs) and by a ratio of $\mathrm{IgG}$ antibodies to pertussis toxin in venous blood at day 28. An antibody titer to pertussis toxin of $125 \mathrm{IU} / \mathrm{mL}$ or greater or a positive PCR result in a respiratory sample defined recent $B$ pertussis infection. M pneumoniae and L pneumopbila infections were determined by PCR from nasopharyngeal swabs. Serologically definitive $M$ pneumoniae infection was defined as $\operatorname{IgM}$ antibodies in the sample on day 1 or day 28 , or a IgG seroconversion or major increase in $\mathrm{IgG}$ antibody levels between day 1 and day 28 . 


\section{Antibiotic Use}

During follow-up, patients in the placebo group could be unblinded and switched to antibiotic treatment according to the treating clinicians' judgments. The physicians could then prescribe any antibiotic they considered appropriate (including amoxicillin, any other penicillin, macrolides, and other). Antibiotic use was defined dichotomously (patient reported intake of antibiotics of 1 dose or more for at least 5 days in the first 10 days after the index physician consultation).

\section{Outcome Measures}

Outcomes were duration of symptoms rated by patients as moderately bad or worse after the initial consultation, symptom severity on days 2 to 4 after the index consultation, and worsening illness, defined as a return visit to the physician with worsening symptoms, new symptoms, new signs, or illness necessitating admission to hospital within 4 weeks after the first consultation. ${ }^{10}$ In addition, we assessed the effects on duration of symptoms until complete resolution and duration of interference with normal activities or work.

\section{Data Analysis}

The course of bacterial LRTI in adults with acute cough was compared with the course of those without bacterial LRTI for all 4 outcomes. Data were analyzed using linear regression models. Simple linear regression was used for symptom severity, Cox regression for the duration of symptoms allowing for censoring, and logistic regression for return visits for new or worsened symptoms. In the multivariable analyses, we controlled all outcomes for the potentially confounding factors of age, current smoking, comorbidity (pulmonary, cardiac, diabetes mellitus) and cough duration before consultation. Finally, we repeated the analysis on all outcomes restricted to the patients who did not use antibiotics to mimic natural course of bacterial LRTI. Another analysis on all outcomes was restricted to those without radiologically proven pneumonia. We expected that $S$ pneumoniae and $H$ influenzae, which are the most common bacteria, may have driven the course of disease, so we performed 2 sensitivity analyses on all outcomes: 1 restricted to those without $S$ pneumoniae infection, and 1 restricted to those without $H$ influenzae infection. Data were analyzed using SPSS 20.0 for Windows (IBM Corp).

\section{RESULTS}

There were 1,021 participants randomized to placebo, and $834(82 \%)$ returned the diary. The baseline characteristics of these 834 participants were similar to those who did not return the diary, except for age (mean age 51 years $[S D=16$ years] vs 43 years $[S D=17$ years $]$ ) (Supplemental Appendix 3, http://www.annfammed. org/content/14/6/534/suppl/DC ). Bacterial LRTI was found in $162(19 \%)$ patients, ranging between $14 \%$ and $26 \%$ in all networks. S pneumoniae (56/834, 7\%) and $H$ influenzae $(56 / 834,7 \%)$ were the most common bacterial microorganisms. M pneumoniae, B pertussis, and L pneumopbila were found in $40(5 \%), 31(4 \%)$, and $1(0.1 \%)$ of 834 participants, respectively.

Patients with bacterial LRTI were more frequently current smokers (33\% vs $24 \%$ with nonbacterial LRTI), had a longer mean cough duration before the index consultation ( 9 days vs 8 days), had a higher physicianrated symptom severity score at day 1 (34 vs 30), and more often showed infiltrates on their chest radiograph (6\% vs $3 \%$ ) (Table 1). Of the 834 eligible participants, $62(7 \%)$ used antibiotics for at least 5 days in the first

Table 1. Baseline Characteristics of Patients With and Without Bacterial Lower Respiratory Tract Infection

\begin{tabular}{|c|c|c|c|c|c|}
\hline Characteristic & $\begin{array}{c}\text { All Patients } \\
(\mathrm{N}=834)\end{array}$ & $\begin{array}{l}\text { Bacterial } \\
\text { LRTI Present } \\
(n=162)\end{array}$ & $\begin{array}{c}\text { Bacterial } \\
\text { LRTI Absent } \\
(n=672)\end{array}$ & $P$ Value $^{a}$ & $\begin{array}{l}\text { Missing } \\
\text { No. (\%) }\end{array}$ \\
\hline Age, mean (SD), y & $51(16)$ & $52(17)$ & $51(16)$ & .450 & $0(0.0)$ \\
\hline Male, No. (\%) & $345(41)$ & $69(43)$ & $276(41)$ & .724 & $0(0.0)$ \\
\hline Current smoker, No. (\%) & $214(26)$ & $53(33)$ & $161(24)$ & .022 & $0(0.0)$ \\
\hline Comorbidity (pulmonary, ${ }^{\mathrm{b}}$ cardiac, $^{\mathrm{c}}$ diabetes mellitus), No. (\%) & $212(26)$ & $46(29)$ & $166(25)$ & .311 & $1(0.1)$ \\
\hline Cough duration before index consultation, mean (SD), $d$ & $9(7)$ & $9(7)$ & $8(7)$ & .021 & $7(0.8)$ \\
\hline Severity score (all symptoms), mean (SD) ${ }^{d}$ & $31(14)$ & $34(14)$ & $30(14)$ & .003 & $22(2.6)$ \\
\hline Infiltrates on chest radiograph present, No. (\%) & $26(3)$ & $9(6)$ & $17(3)$ & .046 & $29(3.5)$ \\
\hline Antibiotic use, No. (\%) & $62(7)$ & $20(12)$ & $42(6)$ & .008 & $0(0.0)$ \\
\hline $\begin{array}{l}\text { COPD = chronic obstructive pulmonary disease; LRTI = lower respirator } \\
\text { a } P \text { value compared patients with and without bacterial LRTI. } \\
{ }^{b} \text { History of COPD, asthma, or other lung disease. } \\
\text { ' History of heart failure, ischemic heart disease, or other heart disease. } \\
\text { d Score for } 14 \text { patients' physician-recorded symptoms summed and scal } \\
\text { e Defined as patient reported intake of antibiotics ( } 1 \text { dose or more) for }\end{array}$ & $\begin{array}{l}\text { to range between } \\
\text { least } 5 \text { days in the }\end{array}$ & $\begin{array}{l}\text { and } 100 \text { at day } 1 . \\
\text { rst } 10 \text { days after the }\end{array}$ & 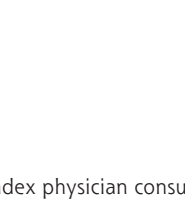 & isp & \\
\hline
\end{tabular}


Table 2. Prognostic Outcomes in Patients With and Without Bacterial LRTI

\begin{tabular}{|c|c|c|c|c|c|c|}
\hline Outcome & $\begin{array}{l}\text { Bacterial } \\
\text { LRTI Present } \\
\text { (n= 162) }\end{array}$ & $\begin{array}{l}\text { Bacterial } \\
\text { LRTI Absent, } \\
(n=672)\end{array}$ & $\begin{array}{l}\text { Crude Analysis } \\
\text { No. }(95 \% \mathrm{Cl})\end{array}$ & $\begin{array}{c}\text { Adjusted } \\
\text { Analysis } \\
\text { No. }(95 \% \mathrm{Cl})^{\mathrm{a}}\end{array}$ & $\begin{array}{c}P \\
\text { Value }^{b}\end{array}$ & $\begin{array}{l}\text { Missing } \\
\text { No. (\%) }\end{array}$ \\
\hline $\begin{array}{l}\text { Time to resolution of symptoms } \\
\text { rated "moderately bad or worse," } \\
\text { median (IQR)d }\end{array}$ & $7(5-15)$ & $7(4-13)$ & $0.89(0.74-1.07)^{c}$ & $0.92(0.77-1.11)^{c}$ & .375 & $1(0.1)$ \\
\hline $\begin{array}{l}\text { Symptom severity score on days } 2 \text { to } \\
4 \text { after consultation, mean (SD) }\end{array}$ & $1.86(1.07)$ & $1.67(1.00)$ & $0.19(0.02-0.37)^{e}$ & $0.21(0.04-0.38)^{e}$ & .014 & $3(0.4)$ \\
\hline $\begin{array}{l}\text { Duration of symptoms until complete } \\
\text { resolution, median (IQR) }\end{array}$ & $15(10-28)$ & $13(8-27)$ & $0.88(0.71-1.10)^{c}$ & $0.92(0.74-1.15)^{c}$ & .471 & $1(0.1)$ \\
\hline Worsening of illness, No. (\%) ${ }^{d}$ & $44 / 162(27)$ & $114 / 660(17)$ & $1.79(1.20-2.67)^{\dagger}$ & $1.82(1.21-2.74)^{f}$ & .004 & $12(1.4)$ \\
\hline $\begin{array}{l}\text { Duration of interference with normal } \\
\text { activities/work, median (IQR) }\end{array}$ & $6(1-10)$ & $5(0-9)$ & $0.91(0.76-1.09)^{c}$ & $0.91(0.76-1.09)^{c}$ & .321 & $6(0.7)$ \\
\hline \multicolumn{7}{|c|}{$\mathrm{IQR}=$ interquartile range; $\mathrm{LRTI}=$ lower respiratory tract infection. } \\
\hline \multicolumn{7}{|c|}{$\begin{array}{l}\text { a Adjusted for age (for each year increase), current smoking, comorbidity, and cough duration before index consultation. } \\
\text { b For adjusted analysis. } \\
\text { ' Hazard ratio. } \\
\text { d Each symptom was scored by the patient from } 0 \text { to } 6 \text {, with } 0=\text { no problem, } 1=\text { very little problem, } 2=\text { slight problem, } 3=\text { moderately bad, } 4=\text { bad, } 5=\text { very bad, } \\
6=\text { as bad as it could be. }\end{array}$} \\
\hline
\end{tabular}

10 days after the index physician consultation. Patients who used antibiotics had a higher physician-rated symptom severity score at day 1 (36 vs 31 ) and were similar to those who did not use antibiotics in terms of mean age (51 years vs 51 years) and comorbidity (31\% vs 25\%) (Supplemental Appendix 4, http://www.annfammed.org/content/14/6/534/suppl/DC1).
A Kaplan-Meier curve for the duration of symptoms rated moderately bad or worse (Figure 1) showed no difference in median and interquartile range of symptom duration between patients with and without bacterial LRTI: 7 days, interquartile ratio $(\mathrm{IQR})=5-15$ days vs 7 days, IQR $=4-13$ days, respectively, for a hazard ratio of $0.92\left(95 \% \mathrm{CI}, 0.77-1.11_{i} \mathrm{P}=.375\right)$. The

\section{Disease Course}

Patients with bacterial LRTI had self-rated mean symptom severity scores on days 2 to 4 that were higher than those without bacterial LRTI $(P=.014)$ and were more likely to make a return visit for new or worsening symptoms $(P=.004)$ (Table 2$)$. Furthermore, excluding patients with radiologically proven pneumonia $(n=26)$ did not result in different findings between those with and without bacterial LRTI for all outcomes. Most return visits were for new or worsening symptoms, and only 2 patients required hospital admission $(1$ from the bacterial LRTI group and 1 from the nonbacterial LRTI group) within 4 weeks after the first consultation. No study-related deaths were noted.

\section{Figure 1. Kaplan-Meier survival curve for the duration of symptoms} rated moderately bad or worse in patients with LRTI.

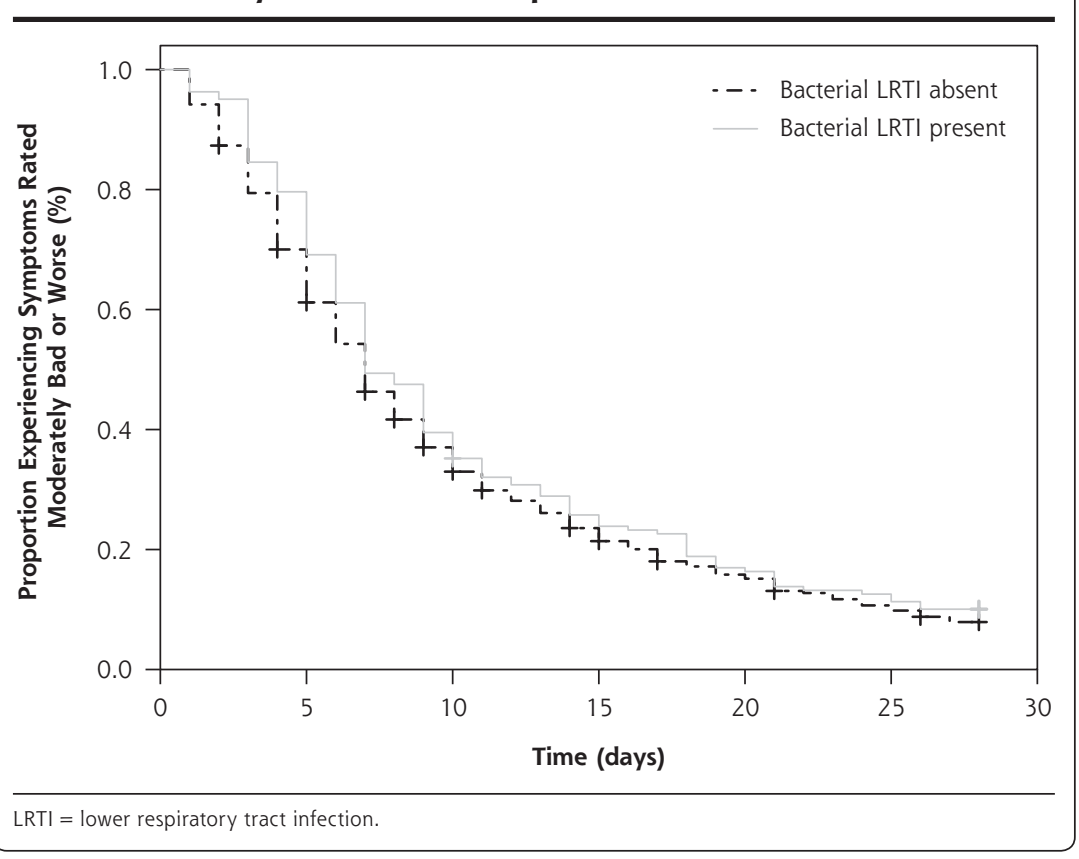


other outcomes did not differ between those with and without bacterial LRTI.

Repeating the analysis restricted to the patients who did not use antibiotics $(\mathrm{n}=772)$ showed that only a return visit for new or worsening symptoms was different between patients with and without bacterial LRTI, 23\% (33 of 42 ) vs $16 \%$ (97 of 619) respectively, $(\mathrm{OR}=1.67 ; 95 \% \mathrm{CI}, 1.06-2.63 ; \mathrm{P}=.029)$ (data not shown in tables). Repeating the analysis restricted to those patients without $S$ pneumoniae infection $(\mathrm{n}=778)$, did not result in different findings. Finally, repeating the analysis restricted to those patients without $H$ influenzae infection $(\mathrm{n}=778)$ showed no differences in course of disease between those with and without bacterial LRTI for all outcomes.

\section{DISCUSSION}

\section{Main Findings}

We found that adult patients who consulted for acute cough in primary care and who had a bacterial pathogen isolated had a slightly worse illness course compared with patients in whom no bacterial pathogen was isolated. The difference is small, however, and clinically not meaningful.

\section{Strengths and Limitations}

As far as we are aware, this study is the first to describe the illness course of a bacterial LRTI in a large study population in primary care. Moreover, the study population was initially not treated with antibiotics, and only a small number of the patients (7\%) were subsequently prescribed antibiotics for their illness episode. As a result, we are able to describe the illness course of bacterial LRTI and assess to what extent it differed from other LRTIs.

One limitation is that more severely ill patients who were immediately referred to a hospital were not included in this study. The severity of our group of patients with bacterial LRTI might be milder than in the general population, and therefore the course of disease is probably not generalizable to sicker patients. Knowledge of the prognosis of bacterial LRTI among severely ill patients, however, will not change management, since those with severe bacterial LRTI still require antibiotic treatment and/or admission to hospital. It should be kept in mind that some patients with initially mild symptoms subsequently do require hospitalization. In our study, however, only 2 patients ( 1 from the bacterial LRTI group and 1 from the nonbacterial LRTI group) were admitted (not immediately) to hospital.

Another possible limitation is misclassification of bacterial LRTI by airway bacterial colonization. We expect this misclassification is limited, because colonization of the lower airways is not likely in symptomatic ambulatory outpatients. In studies where $H$ influenzae and $S$ pneumoniae have been identified by conventional methods in healthy individuals, colonization was estimated maximally at $10 \% \cdot{ }^{15,16}$ Moreover, in our study, the proportion of patients with chronic obstructive pulmonary disease (COPD), in whom airways can be colonized with $H$ influenzae ${ }^{17}$ in severe COPD, was small $(5 \%, 45$ of 834$)$.

Finally, it was not possible to report the full disease course in 7\% (59 of 833) of the patients, because these patients still reported moderately bad or worse symptoms at day 28 .

\section{Comparison with Existing Literature}

The prevalence of patients with bacterial LRTI and radiographic evidence of pneumonia $(1.1 \%, 9$ of 834$)$ in this study is lower than the $5.9 \%$ (14 of 236) reported in a study from Hopstaken et al. ${ }^{18}$ The higher proportion of bacterial pneumonia in that study could be explained by difference in eligibility criteria. Regarding return visits, (27\% in our study) Macfarlane et al reported $21 \%$ (28 of 135 ) return visits for the same illness in LRTI within a month. ${ }^{1}$

\section{Implications for Practice}

Because the illness course of bacterial LRTI is generally mild, uncomplicated, and similar to that of nonbacterial LRTI, physicians can reassure patients that LRTI, even if bacterial, is a self-limiting condition, and that rather than immediately prescribing an antibiotic, a strategy of watchful waiting should be considered.

To read or post commentaries in response to this article, see it online at http://www.annfammed.org/content/14/6/534.

Key words: bacteria; infection, lower respiratory tract infections; cough; prognosis; primary health care; randomized clinical trial

Submitted February 8, 2016; submitted, revised, April 29, 2016; accepted May 9, 2016.

Funding support: This study was part of the GRACE project (http:// www.grace-Irti.org), funded by the 6th Framework Program of the European Commission (Reference: LSHM-CT-2005-518226). The GRACE project has been financially supported through the European Science Foundation (ESF), in the framework of the Research Networking Programme TRACE (http://www.esf.org.trace) and by the Research Foundation Flanders (FWO; Belgium). The current analysis was supported by the $\mathrm{SBOH}$ (http://www.sboh.nl), employer of Dutch general practitioner trainees.

Disclaimer: The funding sources were not involved in the design, conduct, analysis and interpretation of the data, nor in the writing of the article.

Ethical approval: Ethical approval for the Netherlands was granted by the Medisch Ethische Toetsing Commissie (METC) of the University 
Medical Center Utrecht (ref 07-179/0). Competent authority approval for the Netherlands was granted by De Centrale Commissie Mensgebonden Onderzoek (CCMO). UK ethical approval was granted by Southampton and South West Hampshire Local Research Ethics Committee (B) (ref 07/ H0504/104). Competent authority approval for the United Kingdom was granted by the Medicines and Healthcare Products Regulatory Agency. Also the other research sites obtained ethical and competent authority approval from their local organizations.

Supplementary materials: Available at http://www.AnnFamFed. org/content/14/6/534/suppl/DC1/.

\section{References}

1. Macfarlane J, Holmes W, Gard P, et al. Prospective study of the incidence, aetiology and outcome of adult lower respiratory tract illness in the community. Thorax. 2001;56(2):109-114.

2. Graffelman AW, Knuistingh Neven A, le Cessie S, Kroes AC, Springer MP, van den Broek PJ. A diagnostic rule for the aetiology of lower respiratory tract infections as guidance for antimicrobial treatment. Br J Gen Pract. 2004;54(498):20-24.

3. Hopstaken RM, Stobberingh EE, Knottnerus JA, et al. Clinical items not helpful in differentiating viral from bacterial lower respiratory tract infections in general practice. J Clin Epidemiol. 2005;58(2): 175-183.

4. Holm A, Pedersen SS, Nexoe J, et al. Procalcitonin versus C-reactive protein for predicting pneumonia in adults with lower respiratory tract infection in primary care. Br J Gen Pract. 2007;57(540):555-560.

5. Wood F, Simpson S, Butler CC. Socially responsible antibiotic choices in primary care: a qualitative study of GPs' decisions to prescribe broad-spectrum and fluroquinolone antibiotics. Fam Pract. 2007;24(5):427-434.

6. Butler CC, Hood K, Verheij T, et al. Variation in antibiotic prescribing and its impact on recovery in patients with acute cough in primary care: prospective study in 13 countries. BMJ. 2009;338:b2242.

7. Akkerman AE, van der Wouden JC, Kuyvenhoven MM, Dieleman JP, Verheij TJ. Antibiotic prescribing for respiratory tract infections in Dutch primary care in relation to patient age and clinical entities. J Antimicrob Chemother. 2004;54(6):1116-1121.

8. Malhotra-Kumar S, Lammens C, Coenen S, Van Herck K, Goossens $\mathrm{H}$. Effect of azithromycin and clarithromycin therapy on pharyngeal carriage of macrolide-resistant streptococci in healthy volunteers: a randomised, double-blind, placebo-controlled study. Lancet. 2007; 369(9560):482-490.
9. Goossens H, Ferech M, Vander Stichele R, Elseviers M; ESAC Project Group. Outpatient antibiotic use in Europe and association with resistance: a cross-national database study. Lancet. 2005;365(9459): 579-587.

10. Little $\mathrm{P}$, Stuart B, Moore M, et al; GRACE consortium. Amoxicillin for acute lower-respiratory-tract infection in primary care when pneumonia is not suspected: a 12-country, randomised, placebocontrolled trial. Lancet Infect Dis. 2013;13(2):123-129.

11. van Vugt SF, Broekhuizen BD, Lammens C, et al; GRACE consortium. Use of serum $C$ reactive protein and procalcitonin concentrations in addition to symptoms and signs to predict pneumonia in patients presenting to primary care with acute cough: diagnostic study. BMJ. 2013;346:f2450.

12. British Thoracic Society Standards of Care Committee. British Thoracic Society guidelines for the management of community acquired pneumonia in adults. Thorax. 2001;56(suppl 4):1-64.

13. Watson L, Little P, Moore M, Warner G, Williamson I. Validation study of a diary for use in acute lower respiratory tract infection. Fam Pract. 2001;18(5):553-554.

14. Hyman CL, Roblin PM, Gaydos CA, Quinn TC, Schachter J, Hammerschlag MR. Prevalence of asymptomatic nasopharyngeal carriage of Chlamydia pneumoniae in subjectively healthy adults: assessment by polymerase chain reaction-enzyme immunoassay and culture. Clin Infect Dis. 1995;20(5):1174-1178.

15. Lieberman D, Shleyfer E, Castel H, et al. Nasopharyngeal versus oropharyngeal sampling for isolation of potential respiratory pathogens in adults. J Clin Microbiol. 2006;44:525-8.

16. Gunnarsson RK, Holm SE, Söderström M. The prevalence of potential pathogenic bacteria in nasopharyngeal samples from individuals with a respiratory tract infection and a sore throat--implications for the diagnosis of pharyngotonsillitis. Fam Pract. 2001;18:266-71.

17. Rosell A, Monsó E, Soler N, et al. Microbiologic determinants of exacerbation in chronic obstructive pulmonary disease. Arch Intern Med. 2005;165(8):891-897.

18. Hopstaken RM, Coenen S, Butler CC, et al. Prognostic factors and clinical outcome in acute lower respiratory tract infections: a prospective study in general practice. Fam Pract. 2006;23(5):512-519. 